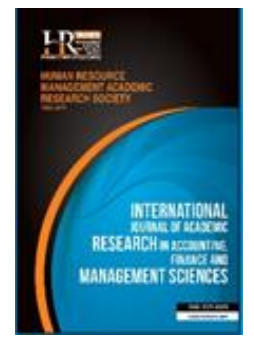

International Journal of Academic Research in Accounting, Finance and Management Sciences

Vol. 8, No.2, April 2018, pp. 287-294

E-ISSN: 2225-8329, P-ISSN: 2308-0337

(c) 2018 HRMARS

www.hrmars.com

To cite this article: Istrate, F. (2018). Impact of Asymmetric Information on the Investment Decision, International Journal of Academic Research in Accounting, Finance and Management Sciences 8 (2): 287-294.

http://dx.doi.org/10.6007/IJARAFMS/v8-i2/4463 (DOI: 10.6007/IJARAFMS/v8-i2/4463)

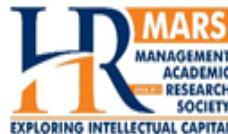

\title{
Impact of Asymmetric Information on the Investment Decision
}

Florentina ISTRATE

University of Craiova, Faculty of Economics and Business Administration 13, A.I. Cuza, 200585, Craiova, Dolj, Romania, E-mail: istrateflorentina@ymail.com

\begin{abstract}
Accountant theoreticians consider the accounting information system as an integral part of the control system of the entire organization, accounting information being an important factor in the investment decision making process. A well-organized financial information system that has in its content relevant managers' indicators, calculated on the basis of accurate and accurate information, acquires an increasingly important role both for the enterprise itself and for its partners. In addition, the resulting indicators will serve to develop a cost-benefit, risk and value diagnosis. The use of financial information by financial analysts is related to four key issues: (1) growth prospects of the economy are based on future expectations regarding the economy, with particular importance to the factors that have a major influence on this (profit, dividend and price of the action); (2) significant factors of the financial market, focusing on identifying the factors that influence the position of the enterprise on the market; (3) investment parameters, taking into account the dividends and the market price in conjunction with the accepted risk; (4) investment strategies where short, medium or long-term investment recommendations are based on two aspects: share price expectations and synchronization in terms of enterprise performance.
\end{abstract}

Key words Adverse selection, moral hazard, investment decision, financial statement, evaluation values

Received: 20 June $2018 \quad$ (c) The Authors 2018

Revised: $09 \mathrm{Jul} 2018$ Published by Human Resource Management Academic Research Society (www.hrmars.com)

Accepted: $28 \mathrm{Jul} 2018$ This article is published under the Creative Commons Attribution (CC BY 4.0) license. Anyone may Published Online: 28 Aug 2018 reproduce, distribute, translate and create derivative works of this article (for both commercial and noncommercial purposes), subject to full attribution to the original publication and authors. The full terms of this license may be seen at: http://creativecommons.org/licences/by/4.0/legalcode

\section{Introduction}

The phenomenon of information asymmetry is often manifested both at the firm level and at the level of investors who have to choose between different ways of investing their own available financial resources. If an investor possesses privileged information, for example that the firm has acquired a license to enable it to substantially increase its turnover and net profits, it will be interested in buying shares at the stock price current, which does not reflect this information.

Even if the investor under consideration only considers a short-term investment, it may record a gain, speculating advantageously the difference between the level of the course (possibly higher) after the public announcement of that information and that of the previous announcement.

The mandatory condition is that the financial market "correctly" understands market information: if, for example, the public appearance of information of the type described above is not correctly received, the level of the course scholarship does not change. We believe that the moment of the creation of a firm is most often related to the intuition of an entrepreneur who has the ability to identify those market sectors that can offer him the opportunity to assert his own comparative advantage in competition with direct or indirect competitors. Although this moment is extremely important, it can not generate virtually any result without the use of external capital through which to implement this idea. In order to attract investors, the entrepreneur must identify the means by which he can convince them to make available their own financial 
resources. For a potential investor, the option to allocate funds available to a person who can not guarantee the ability to increase his fortune is a crucial moment. Any financial decision is taken under uncertainty. The only objective attempt is to reduce as much as possible this uncertainty.

Therefore, the real world constantly confirms that there is a state of information asymmetry: some of the agents acting on the market are more informed than the others. Under these circumstances, studying the level of information of the agents and the mechanisms by which this can be achieved as fully and as correctly as possible becomes extremely useful.

\section{Literature review}

\subsection{Considerations concerning the asymmetry of accounting information}

Modern financial theory attempted to ameliorate certain results obtained on account of modeling based on the less realistic hypotheses involved in efficient market theory. Much of the study is related to information asymmetry. The existence of an asymmetry of information among the various investors acting on the financial market in Romania leads us to the idea of the possibility of significant risks of adverse selection or moral hazard.

In principle, the adverse selection assumes that individuals will make the optimal decision based on their private information, without knowing whether they are correct or not and actually.

Another application of the theory of adverse selection is the issue of shares. Managers have an interest in issuing shares at times when they are overvalued on the market. If the risk of adverse selection occurs at the time of the investment decision, market agents are not able to distinguish between projects characterized by varying degrees of performance, moral hazard (hazard) occurs after the decision has been made. The moral hazard (hazard) is also manifested in the company's financial management. Thus a manager can guarantee a certain level of financial performance associated with the company he leads, through the performance he has recorded in the past through his relationships with other stakeholders, etc. However, this behavior may change in the future, and shareholders may experience a reduction in their wealth. Also, asymmetry of information can generate abnormal gains for certain stakeholders. As with mandate issues, it is extremely difficult to identify concrete cases in which some individuals benefit from the strategic position held in the information flow in order to obtain such abnormal gains. These are rather suspicions than certainties, and statistics can only help us to validate a certain hypothesis, as a statistical trend, as a possibility.

At the same time, we believe that information becomes an increasingly important resource, including in the company's financial management. It is appropriate in this respect to assert a true market, on which the sale of information will be realized. Thus, the information vendor must be concerned not only with covering the costs of obtaining and processing information but also making a profit. On the other hand, the buyer of information must be interested in purchasing them only to the extent that they can use them in the future to increase their utility function.

From the point of view of financial market information, the performance of the issuing company in the past, which can be used to substantiate future performance, different forecasts for future developments, the acquisition of trademarks, patents or licenses, etc?

In this context, financial analysts process this information and offer a set of suggestions about the future trend of the stock market. Although a certain segment of investors is using their services (they are perfectly assimilated with internal investment fund analysts or other large securities portfolio managers), the information is also transferred to the public, which does not bear any cost.

Thus, some investors can copy the behavior of those who are informed (and who pays for this information) by buying or selling titles in the same way as they do. In the long run, the act of informing you appears unnecessarily under these conditions, making it even more cost-effective to wait for the reaction of other market agents, which would lead to an incorrect evaluation of the securities.

\subsection{Evaluation of financial assets under conditions of information asymmetry}

A particular peculiarity is the valuation of financial assets under asymmetric conditions on the capital market because the relationship between profitability and market risk is very poor but direct. 
Most valuation theories of financial assets are based on the underlying assumption that investor information is homogeneous, ie all investors have the same expectations as to the income that these assets hold. The best-known model is CAPM (Capital Asset Pricing Model) proposed by Sharpe (1964), Lintner (1965a) and Mossin (1966). Conversely, the theories in a (more realistic) context where there is an imbalance of information between agents have not been used enough to assess securities. In particular, too few models on the valuation of securities take into account the extraction of the signal from the equilibrium price.

The notion of information asymmetry in financial reporting and its broader implications have enjoyed remarkable attention in recent years. The origin of this concept dates back to the 1970s when the three researchers, Michael Spence, George Akerlof and Joseph Stiglitz, made numerous debates later known as the information asymmetry theory (Barkley, 2002).

The so-called "Grossman-Stiglitz" paradox points out that if a market is informally efficient, that is, all relevant information is reflected in market prices, and then no agent calls for it to acquire this costly information. But if no one is informed, then it becomes imperative for an agent to get informed. Therefore, there is no effective balance in the informational sense.

Most valuation models that consider differently-informed agents place them in a context where there is a multitude of investors who each have information about the future pricing of the risky asset. Therefore, the information is heterogeneous. Hayek (1945) claims that the equilibrium price sends signals to information available to investors. Some authors formalized the framework proposed by Hayek and studied the aggregation of information through the equilibrium price, considering only a risky asset (Grossmann, 1976, Hellwig, 1980). The equilibrium price reflects all this information. On the contrary, other studies consider that there is only one information held by some informed investors (Grossman and Stiglitz, 1980). In this case, we talk about asymmetric information. The balance price transfers some (or all) information to uninformed investors.

Informational asymmetry creates an imbalance between transaction partners with unfair results. Of course, in this position, the sale price of the merchandise does not reflect the fair and intrinsic value, depending on the level of informational awareness, differences that are higher or lower than its fair values. We distinguish, in this case, two types of information restrictions: moral hazard and adverse selection.

In terms of moral hazard, accounting literature studies this concept in terms of the relationship between associates and management, while the adverse selection concentrates and studies especially the relationships between the stakeholders. As a result, if there was no adequate information on market values, buyers of these shares prefers not to pay more for them, while vendors are willing to sell their shares at a high price. The specialized literature justifies the existence of the spread between bids and asks prices as a result of the asymmetry of information between dealers. It is also assumed that the level of asymmetric information is higher as this difference increases.

Stoll (1989) and Aitken and Frino(1996) have shown that this difference together with the spread between sale and purchase prices is the main component of transaction costs. By analyzing the spread between the sales price and the purchase price, George et al. (1991) classified this difference in three costs, as shown in Figure 1.

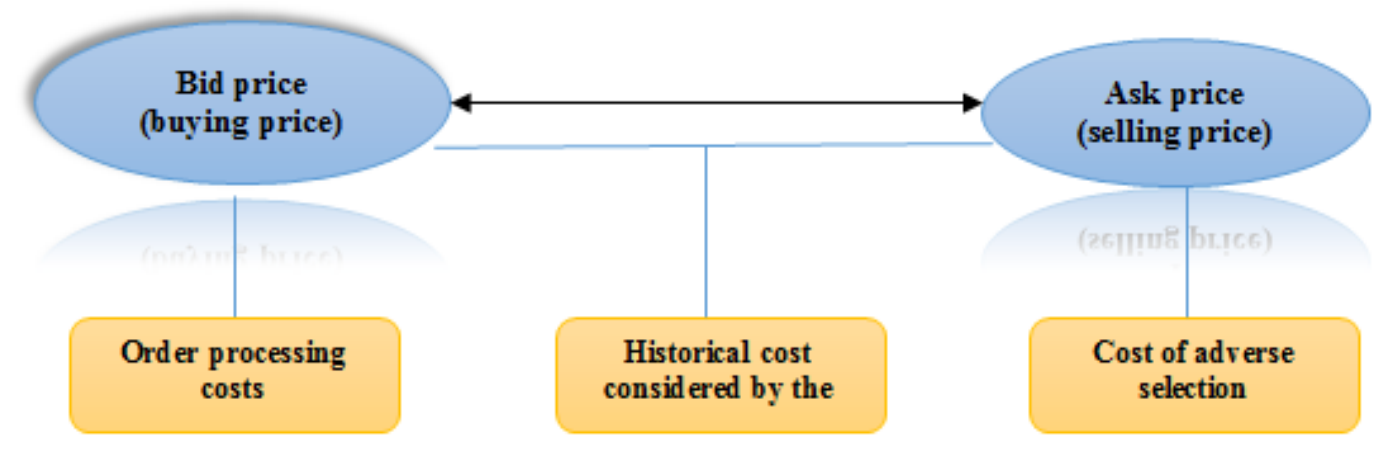

Source: Author's view

Figure 1. The composition of the difference cost spread between bid and ask prices 
Last but not least, given that dealers are acting among a professional and well-informed guild, they are increasing part of the cost of adverse selection to offset the probable losses in future transactions. Improving the quality of accounting information leads to the reduction of informational asymmetry between market participants, and thus the component of the cost of adverse selection will decrease.

Investigating the information asymmetry in figure 2. the types of asymmetric information and their relationship with the objectives of financial reporting are presented.

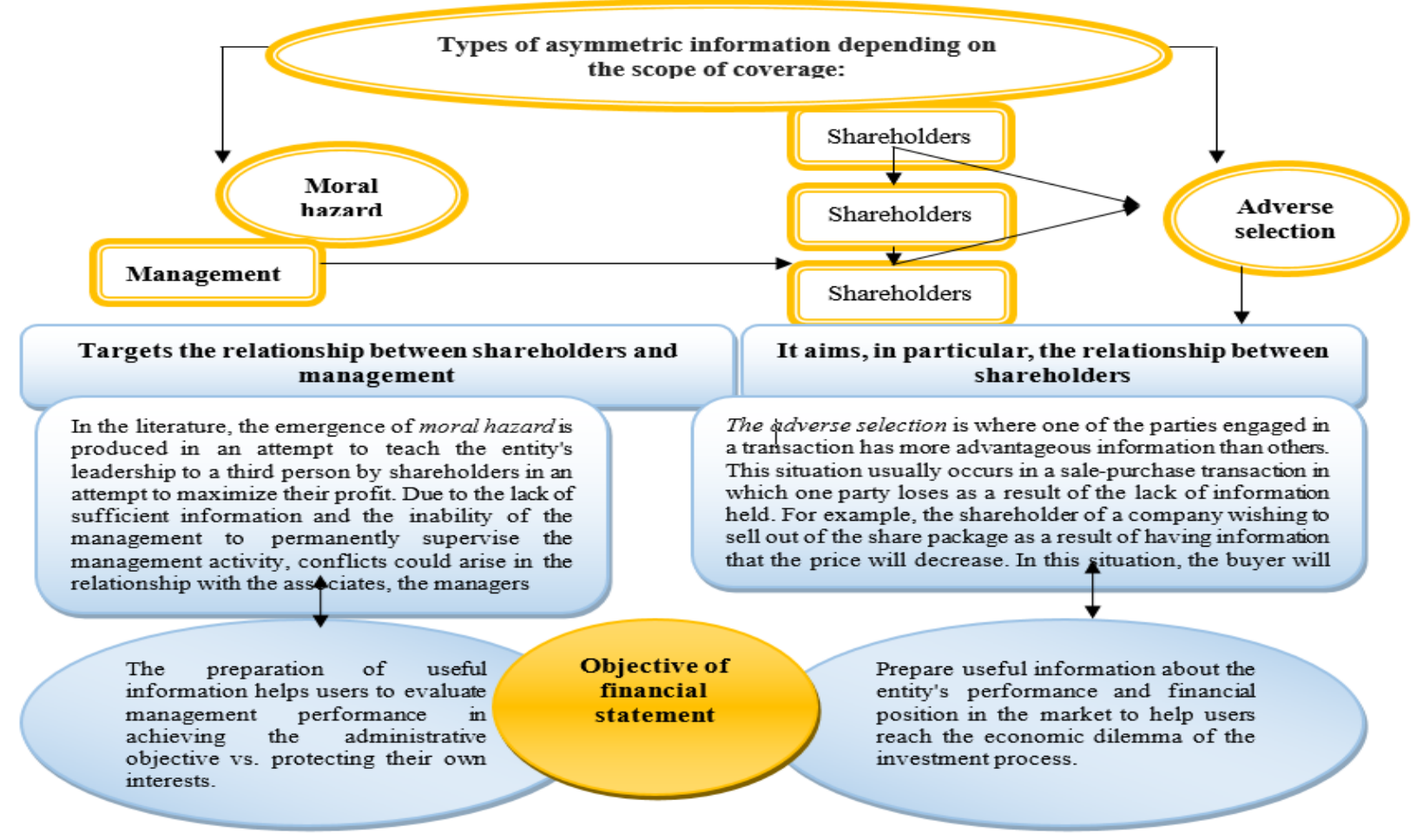

Source: Author's view

Figure 2. Types of asymmetric information and their link to financial reporting objectives

To this end, in order to reduce the level of information asymmetry among market participants and to achieve a high level of market efficiency, major changes are needed in the accounting system for the preparation and provision of sufficient and timely information for to help investors in the process of investing or disinvesting. In this respect, the accountancy profession has contributed by preparing international standards capable of providing qualitative and helpful information to its users.

Even if the assessment of the factors influencing the prices is not disputable, the correction made, the analyzes performed, the recommendations offered guarantee only the probability of a good choice of the meaning of the operation - sale or purchase.

\section{Research metodology of research and results}

We believe that we can also talk about assets valuation models under asymmetric information and when trading non-financial assets on the commodity exchange.

Adaptation of models is dependent on the type of contract that concerns the transaction: spot, forward, futures. ${ }^{1}$

\footnotetext{
${ }^{1}$ The spot transaction is an agreement between two trading partners in which one purchases one and sells a certain amount of commodity at a certain price "on the spot", such as: exchange, trading of shares, trading in commodities.

The forward contract is an intermediate step between the spot contract and the futures contract characterized by the fact that delivery and payment is made at maturity. Therefore, the two trading partners negotiate the quantity, price and delivery term called maturity. Consequently, the buyer is certain that at time t1 he will receive q0 at the price p0 by removing information asymmetry
} 
For example, we will refer to the forward contract and start from the following familiar dates:

a) the evolution of the exchange rate between 3 January 2018 and 14 May 2018, according to the chart in figure no. 3

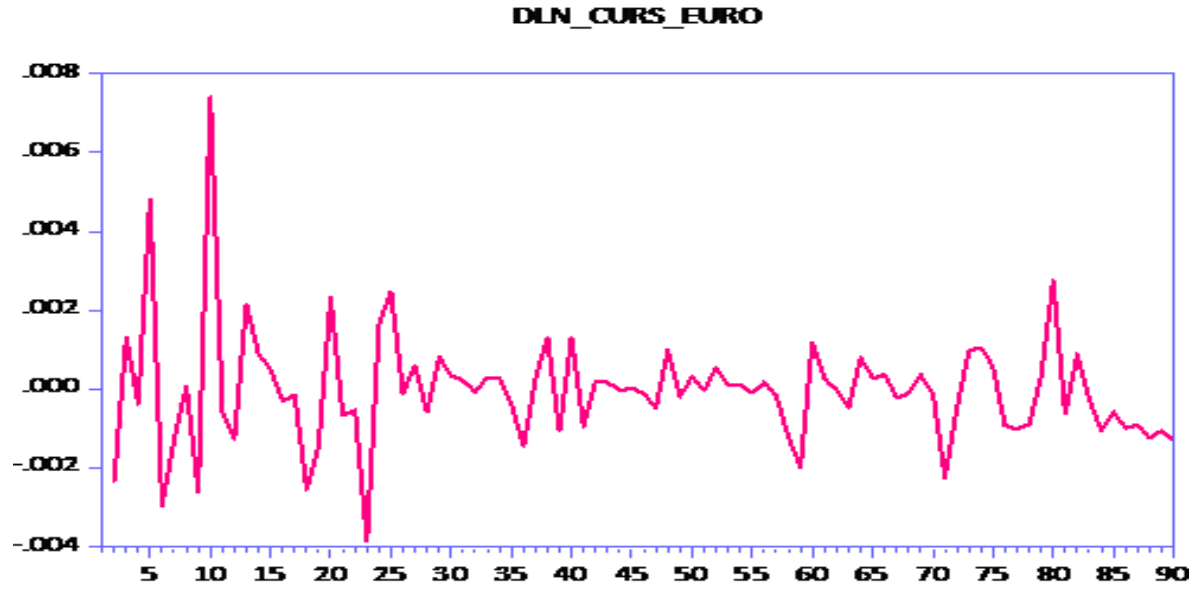

Source: Made by the author on the basis of the daily rate communicated by the National Bank of Romania between 3 January and 9 May 2018

Figure 3. The evolution of the exchange rate between January-May 2018

b) the elements of the contract:

- date of negociation $t_{0}-6$ of March 2018;

- due date $t_{1}-4$ of June 2018;

- the known income of the vendor (Rv) -100.000 euros;

- the lei/euro (p0) rate at time $t_{0}-4,6596$ lei/euro

- random offering of asset $z-600.000$ lei

- the lei/euro $\left(p_{1}\right)$ rate at time $t_{1}=$ ?

- income expectancy (Sv) =?;

- the contract is forward type and is concluded between a seller in France and a Romanian buyer

c) the calculation of income expectancy

As the buyer's interest is to achieve a future income, under the given conditions we will calculate the income expectation at time $t_{0}$ based on the relationship

$$
\begin{aligned}
& S v_{0}=z-R v^{*} p_{0} \\
& S v_{0}=600.000-100.000 * 4,6596=134.040 \text { lei }
\end{aligned}
$$

But the 100,000 euros will only be bought in three months (June 6, 2018) when the RON / Euro rate is not known and therefore the purchaser's purchase price that is unable to (and determine the income hope)

d) application of VaR model

Using the principles of the VaR model, we tried to estimate a possible exchange rate at the time $t_{1}$ and the income hope the buyer can achieve in a risky fashion.

For this we started from the calculation of the average exchange rate recorded between January May 2018 (Figure 2), using the EViews program:

The futures contract is an agreement between two trading partners on the delivery of a standard quantity of merchandise at a time t1 called maturity at the negotiated price $\mathrm{p} 0$ established at the time of the transaction 


\begin{tabular}{|lc|}
\hline & EURO_Rate \\
\hline Mean & 4.654959 \\
Median & 4.657600 \\
Maximum & 4.667900 \\
Minimum & 4.625600 \\
Std. Dev. & 0.009313 \\
Skewness & $(1.292266$ \\
Kurtosis & 4.079773 \\
& \\
Jarque(Bera & 29.42142 \\
Probability & 0.000000 \\
& \\
Sum & 418.9463 \\
Sum Sq. Dev. & 0.007719 \\
Observations & 90 \\
\hline
\end{tabular}

Figure 2. Descriptive statistics of the exchange rate

For the purpose of applying the principles of the VaR mode ${ }^{2}$ we considered the following:

- the average euro/lei exchange rate during the period January-May 2018, calculated on the basis of the daily fluctuation, was 4.65959 lei according to Figure 2;

- the number of fluctuation days ( $\mathrm{t}$ ) of year 2018 was 90 days;

- estimated volatility for June is $9 \%$;

- daily volatility: $\mathrm{VZ}=\mathrm{VA} * \mathrm{Vt}$, where $\mathrm{VA}=$ annualized volatility, where: $\mathrm{VZ}=9 / \mathrm{V} 90=0,009486832$ In this context, the calculation of the possible levels that the euro/lei exchange rate could be recorded at $\mathrm{t} 1$ is shown in table 3.

Table 3. Calculation of the exchange rate level euro/lei on 6 June 2018 (moment $t_{1}$ )

\begin{tabular}{|l|l|}
\hline \multicolumn{2}{|c|}{ A standard deviation } \\
\hline Maxim & $\mathrm{H}=4,654959 *(1+1 * 0,009486832)=4,6991198$ \\
\hline Minim & $\mathrm{L}=4,654959 *(1(1 * 0,009486832)=4,610798$ \\
\hline
\end{tabular}

\begin{tabular}{|l|l|}
\hline \multicolumn{2}{|c|}{ The second standard deviation } \\
\hline Maxim & $\mathrm{H}=4,654959 *(1+2 * 0,009486832)=4,74328$ \\
\hline Minim & $\mathrm{L}=4,654959 *(1(2 * 0,009486832)=4,566637$ \\
\hline
\end{tabular}

Source: Calculations belong to the author

Considering that the vendor's known income is 100,000 euros and the random offer of the $z$ asset of 600,000 lei, the VaR calculation for the value of the leu on the $95 \%$ and $99 \%$ confidence interval will be the following:

- for the first standard deviation

$\operatorname{VaR}=0,009486832 * 600.000=5.692$ lei

\footnotetext{
${ }^{2}$ The VaR model serves to quantify market risk in monetary units to which a probability and time horizon are connected. T.Sydor (2007) defines VaR as the maximum loss of portfolio value under normal market conditions.

For a confidence level and a given holding period, three factors must be considered for estimating the potential loss that may result from a particular portfolio:

- volatility (which typically has an annualized value), the calculation of which takes into account the maturity period of the investment whose square root is used to adjust volatility);

- the time horizon (one day or one month) is an important factor for determining volatility. The longer the time horizon, the higher the VaR value;

- the level of trust (depends on market liquidity and, the higher, the higher the value

- VaR).

VaR is estimated by the parametric method (variation - covariance that is based on the hypothesis that the law attached to the risk factors follows a theoretical law, and the choice of each parameter is made according to various criteria, including depending on the aim pursued and the level of risk that can be accepted, provided that the portfolio remains stable within the period under review (which is why periods of up to 30 days are chosen).

The expression of VaR can be one in absolute value (RON, MILLION, EUR or MILLION) or percentage and can be calculated individually (on each subunit) or aggregated at the level of the whole company, by risk type, by financial instruments, etc.

Studies undertaken show that the most common confidence intervals range from $95 \%$ to $99.9 \%$.
} 
- for the second standard deviation

$\operatorname{VaR}=0,009486832 * 2 * 600.000=11.384$ lei

Thus:

$>$ in the fluctuation range of the exchange rate from 4,610,798 to 4,699,1198 there may be an increase in the income hope, or a loss of 5,692 lei compared to the initial expectation of the buyer;

$>$ In the range of 4,566,637-4,74328 there may be an increase in the income hope, or a loss of 11,384 lei compared to the initial expectation of the buyer.

The fluctuation of the exchange rate determines the occurrence of trading of assets with risk under uncertainty and puts a mark on the profit obtained that is reflected in the financial statements of the company.

The capital market, while at the same time competitive and very complex, has, as we have shown, unpredictable coordinates. Under these circumstances, in order to make sufficiently good decisions, market operators and stock market analysts need to have information and assessments obtained over time but that are relevant at present. Additionally, the performance decision maker in uncertainty must achieve a level of rationality that allows him to distinguish between relevant and insignificant information and, if necessary, to promote in some circumstances extracutaneous initiatives and actions.

The impressive development of capital markets and multinational companies' work has made it clear that there is a need for high-quality accounting standards on which to base financial reporting to achieve comparability at global level. But achieving such an objective can not be achieved without difficulty. Obstacles are generated on the one hand by the fact that at international level the differences between the different accounting systems still exist as a result of the manifestation of the factors that sustain them and on the other hand the difficulties of implementing the international financial reporting standards in countries with different accounting traditions (for example: the complexity of international standards, language difficulties, terminology, interpretation, etc.)(Gorgan, 2011).

As a result of this schematic model, the information deficit occurs on the market when, from the point of view of the participants, insufficient information regarding the profitability or profitability of the securities is communicated/disclosed while the quality deficit shows that the information submitted in terms of criterion quality, are not as reliable as expected.

Moreover, the accountancy profession has faced with time the problem of the audited activity deficit, which is due to the gap between the exercise of the professional audit activity, its objectives and results, as well as the expectations of the entity (Salehi, 2008b). Also, the management of the company must clearly express the objectives of the business in order to finally determine whether the scope of the business was achieved or not, in the absence of its clear expression, a lack of communication from the management. However, there may also be differences in terms of how users interpret data by applying distinct methods. Last but not least, as a result of the accumulation of the abovementioned deficiencies, it provokes the "perception deficit", which shows that the information to be presented in connection with the capital market is understood differently, and ultimately leads to the "difference value".

The difference in value relates to the difference between the entity's market value and management's perception of the intrinsic value of the company's shares. The greater the gap, the greater the difference in value, and this difference is measured between the sale price of a company's shares and their intrinsic value. Also, the management of the company must clearly express the objectives of the business in order to finally determine whether the scope of the business was achieved or not, in the absence of its clear expression, a lack of communication from the management.

However, there may also be differences in terms of how users interpret data by applying distinct methods. Last but not least, as a result of the accumulation of the abovementioned deficiencies, it provokes the "perception deficit", which shows that the information to be presented in connection with the capital market is understood differently, and ultimately leads to the "difference value". The difference in value relates to the difference between the entity's market value and management's perception of the intrinsic value of the company's shares. The greater the gap, the greater the difference in value, and this difference is measured between the sale price of a company's shares and their intrinsic value. 


\section{Conclusions}

The conclusion is that, in order to avoid informational risks that can lead to loss of credibility of the enterprise to investors and all users of information, it is necessary to observe three essential conditions: confidentiality, availability and integrity.

Analyzing the empirical studies undertaken in the field, we propose several possible solutions for solving the problems of the adverse selection and diminishing the informational asymmetry:

- the creation of optimal contracts between managers and investors, providing for the complete provision of financial information considered confidential by management;

- "normalization", e.g the issuance of regulations whereby managers are required to provide complete private information on the actions taken;

- employing financial intermediaries (e.g financial analysts, rating agencies, etc.), which will aim at obtaining internal information, etc.

\section{References}

1. Aitken M, Frino A.(1996), The determinants of market bid-ask spreads on the Australian Stock Exchange: Cross-sectional analysis, Account.Finan., 36 (1): 51-63.

2. Akerlof, G.A.(1970), The market for lemons: quality uncertainty and the market mechanism, Quarterly Journal of Economics, 84, pp. 488-500.

3. Barkley R.J.(2002), A Nobel Prize for Asymmetric Information: The Economic Contributions of George Akerlof, Michael Spence, and Joseph Stiglitz, Review of Political Economy, James Madison University

4. George TJ, Kaul G, Nimalendran M. (1991), Estimation of the bid-ask spread and its components: A new approach. Rev. Finan. Stud., 4(4):623-656.

5. Gorgan, C.(2011). Financial reporting changes un the context of the international accounting convergence.Universitatea Tibiscus. Anale.Seria Stiinte Economice, XVII, 722-729.

6. Grossman, S.(1976), On the efficiency of competitive stock markets where trades have diverse information, The Journal of Finance, vol.XXXI, no.2.

7. Grossman, S. e Stiglitz, J. (1980), On the impossibility of informationally efficient markets, American Economic Review, vol. 70, pp. 393-408.

8. Hayek, F. A. (1945), The use of knowledge in society, in Hayek 1976a.

9. Lintner, J. (1965a), The Valuation of Risk Assets and the Selection of Risky Investments in Stock Portfolios and Capital Budgets, Review of Economics and Statistics. February, 47, pp. 13-37.

10.Mossin, Jan. (1966), Equilibrium in a Capital Asset Market, Econometrica. October, 35, pp. 768-83.

11.Tripathy N. et R.L. Peterson (1991), The Relationship between OTC Bid-Ask Spreads and Dealer Size: the Impact of Order-Processing and Diversification Costs, Journal of Financial Research, vol. 14, n. 2, pp. 117-127.

12.Van Ness B., R Van Ness. et R.Warr (2001), Determinants of Adverse Selection on the NYSE and Nasdaq : a Paired Comparison, working paper, disponible sur le site www.ssrn.com.

13.Salehi, M. (2008b), The Role of Financial Intermediaries in Capital Market. Zagreb Int. Rev. Econ. Bus., 6(1): 97-109.

14.Sharpe, William F. (1964), Capital Asset Prices: A Theory of Market Equilibrium under CondiThe Capital Asset Pricing Model 23 tions of Risk, Journal of Finance. September, 19, pp. 425-42.

15.Spence, A.M. (1973) Job market signaling, Quarterly Journal of Economics, 87, pp. 355-374.

16.Stiglitz, J.E. \& Rothschild, M.E. (1976) Equilibrium in competitive insurance markets, Quarterly Journal of Economics, 90, pp. 629-649.

17.Sydor, T. (2007), La Value at Risk, EURIS (Euro Institut DțActuariat Jean Diedonné.

18.Stoll H. (1989), Inferring the components of the bid-ask spread: Theory and empirical tests. J. Finan., 44: 115-134.

19.Welker M. (1995), Disclosure Policy, Information Asymmetry and Liquidity in Equity Markets, Contemporary Accounting Research, vol. 11, n. 2, pp. 801-827. 